Research Article

\title{
Temperature Field and Gradient Effect of a Steel-Concrete Composite Box Girder Bridge
}

\author{
Haoxu Li $\mathbb{D},{ }^{1}$ Zhiguo Zhang, ${ }^{2}$ and Nianchun Deng $\mathbb{D}^{1,3}$ \\ ${ }^{1}$ College of Civil Engineering and Architecture, Guangxi University, Nanning 530004, China \\ ${ }^{2}$ School of Civil Engineering, Shijiazhuang Tiedao University, Shijiazhuang 050043, China \\ ${ }^{3}$ Key Laboratory of Disaster Prevention and Structural Safety of Ministry of Education, Guangxi University, \\ Nanning 530004, China \\ Correspondence should be addressed to Nianchun Deng; dengnch@gxu.edu.cn
}

Received 21 July 2021; Accepted 25 August 2021; Published 10 September 2021

Academic Editor: Luigi Di Sarno

Copyright (C) 2021 Haoxu Li et al. This is an open access article distributed under the Creative Commons Attribution License, which permits unrestricted use, distribution, and reproduction in any medium, provided the original work is properly cited.

\begin{abstract}
To study the effect of the temperature field and gradient of a steel-concrete composite box girder bridge, a $5 \times 35$ continuous composite box girder bridge is used as the research object. The temperature measuring point is set by selecting a typical cross section, and the temperature change data are measured. The temperature field of the different positions in the composite box girder bridge is studied, the global and local temperature differences are compared, and the law of temperature distribution and the main factors affecting the temperature field are formulated. The most unfavourable expression function of the vertical temperature gradient of the section is simulated using the measured data, the existing standard temperature gradient mode is compared, the finite element model of the bridge is established, and the influence of the actual temperature gradient mode on the stress and deformation of the composite girder is further analysed. The conclusions show that the temperature differences of different azimuth sections and the local temperature differences between the steel and concrete joint parts of the steel-concrete composite box girder bridge are not significant. The temperature gradient heating and cooling model fitted by the measured temperature field can be used as a reference for the structural design of similar local bridges.
\end{abstract}

\section{Introduction}

A steel-concrete composite box girder bridge is directly exposed to the environment, and the energy exchange between the bridge and the surrounding environment affects the temperature field of the composite box girder bridge [1-5]. For bridges with steel box girders, temperature changes impact the stress and deformation of the main girder, resulting in changes in the characteristics of the whole bridge [6-11]. Many factors, such as solar radiation intensity, bridge orientation, climatic conditions, materials, and bridge cross section, will affect the temperature field of composite box girder bridges [12-16]. Thus, the temperature field of steel-concrete composite box girder bridges can be extremely complex. However, due to periodic solar radiation and the complex heat exchange between the structure and air, the temperature at different locations of such a bridge varies greatly with time. Therefore, further investigation of the temperature field of steel-concrete composite box girder bridges and analysis of the temperature gradient effect will provide key information for the design of steel-concrete composite box girder bridges and their maintenance during long-term service [17].

In recent years, bridge temperature monitoring technology has provided an effective method to study the temperature field and its influence on steel-concrete composite box girder bridges based on monitoring data [18-20]. A large number of monitoring systems [21-25] are installed on steel-concrete composite box girder bridges worldwide, which is helpful to statistically analyse the temperature field of steel-concrete composite box girder bridges. For example, Zhou and Sun [26] studied the temperature effect of bridges in daily and annual cycles. In addition, some studies use statistical analysis techniques to predict long-term extreme 
thermal effects based on limited short-term data [5, 27-33]. Although these measurements capture the temperature behaviour of the bridge on-site, the number of measuring points is usually limited due to the high cost of the monitoring system. In addition, the amount of data collected at each monitoring location is limited because it depends on the service life of the monitoring system.

With the rapid development of numerical simulation technology, the finite element method has been widely used to calculate the temperature effect under complex boundary conditions. For example, Wang et al. [34] investigated the individual and coupling effects of the vertical, transverse, and longitudinal temperature gradients of bridges by using the finite element method. Lawson et al. [35] used heat flow to analyse the temperature gradient of concrete box girders and composite steel bridges, which provides a better understanding of the thermal effect of bridges under extreme climate conditions. Environmental conditions such as solar radiation and air temperature fluctuate greatly over time and have significant uncertainty, which makes it difficult to compare the simulated temperature field with the field measurement results. In addition, due to the large and complex bridge system and complex geometric structure of steel-concrete composite box girder bridges, it is challenging to simulate the temperature field of this type of bridge over a long period. Therefore, the simulation of the related heat conduction requires extensive calculation.

In view of the above problems, this paper studies the temperature field of a steel box girder, analyses the temperature value of each measuring point, discusses the simulated temperature gradient effect, and further analyses the influence of the measured fitting temperature gradient model on the stress and deformation of the composite girder. In this paper, the temperature gradient model fitted with the measured temperature field can provide a reference for the structural design of similar local bridges and further deepen the understanding of the temperature distribution and change in steel-concrete composite box girder bridges.

\section{Design and Methods}

The Viaduct fifth joint is a $5 \times 35 \mathrm{~m}$ continuous box composite beam with a $24 \mathrm{~m}$ bridge deck width and 6 two-way lanes, including a motorway with a full width of $22.5 \mathrm{~m}$, an anticollision guardrail with a full width of $1.0 \mathrm{~m}$, and a central separation guardrail with a full width of $0.5 \mathrm{~m}$. It has an open channel section overlaid with a concrete slab and a $1.5 \%$ cross slope of the bridge deck, formed by an unequal height of the web. The $35 \mathrm{~m}$ standard span is a composite box girder with equal cross section. The average height of the box girder is $1.75 \mathrm{~m}$, of which the steel box girder is $1.40 \mathrm{~m}$ high and the concrete slab is $0.35 \mathrm{~m}$ thick.

The steel beam material is Q345qD, and the beam body was fabricated by prefabrication and on site assembly. The section of the steel beam is a single box with four chambers, the width of the upper flange plate is $0.60 \mathrm{~m}$, and the thickness is $26 \mathrm{~mm}$. The bottom plate is $16.00 \mathrm{~m}$ wide and $20 \mathrm{~mm}$ thick. The webs on both sides are $1.31 \mathrm{~m}$ high and $16 \mathrm{~mm}$ thick. The steel box girder adopts the transverse diaphragm structure of a web vertical rib + top and bottom plate transverse ribs. The spacing of the diaphragm is $1.00 \mathrm{~m}$ at the pier top and $2.0 \mathrm{~m}$ at the midspan. The concrete was poured in the steel box at the top of the middle pier, and the concrete and the steel beam were connected together through the bottom plate stiffening rib of the pier top. The fifth steel box girder is divided into 46 beam sections, the section sizes are $1.92 \mathrm{~m}, 3 \mathrm{~m}$, and $4 \mathrm{~m}$, and the unit weights are 16.3 t, 19.3 t, and 25.9 t, which are manufactured by the factory. After transportation to the site, temporary piers and supports were installed by lifting and erecting in sections. The temporary piers and supports were lifted into place from the small mileage to the large mileage, then retested and adjusted, and finally welded together.

The bridge deck is made of C50 high-performance concrete, which is cut vertically and horizontally and was prefabricated in blocks. The thickness of the bridge deck is $0.35 \mathrm{~m}$, and the types are side slabs, secondary middle slabs, and middle slabs. The sizes of these slabs are $2.52 \mathrm{~m} \times 2.6 \mathrm{~m}, 3.1 \mathrm{~m} \times 4.65 \mathrm{~m}$, and $3.1 \mathrm{~m} \times 9 \mathrm{~m}$, nearly $3.5 \mathrm{~m}$. With the precast slab in place, the overlapping distance between the precast slab and the top flange plate and the top diaphragm is $50 \mathrm{~mm}$, the width of the longitudinal cast-in-place joint of the bridge deck is $500 \mathrm{~mm}$, and the width of the transverse cast-in-place joint is $400 \mathrm{~mm}$. The whole cast-in-place bridge deck is used at both ends of the whole bridge, the cast-in-place material is C50 nonshrinkage micro-expansion compensation concrete, and the expansion rate is $2 \times 10^{-4}$. The discontinuous construction method was adopted for the concrete bridge deck. First, the deck in the positive bending moment area was constructed to join the steel beam, and then the composite section was used to carry the structural stress as soon as possible. Then, the deck in the negative bending moment area was constructed to greatly reduce the tensile range and value. In the negative moment area, before the bridge deck was combined with the steel beam, the fulcrum was lifted first, and then it fell back into position after the bridge deck was combined and hardened, and a compressive stress was applied to the bridge deck to reduce the negative moment on the pier top. The layout of the whole bridge is shown in Figures 1 and 2.

First, to determine the temperature change on the cross section of the bridge, temperature sensors are embedded in the middle of the first span, the second span, and the third span of the steel-concrete composite box girder bridge, and on sections \#16 and \#17, the pier top is used to measure the temperature distribution. Among them, 4 measuring points are arranged in the deck concrete, and 6 measuring points are arranged in the steel box girder. The specific test section is shown in Figures 3 and 4, with the measuring point (field sensor) arrangement.

Table 1 shows the meteorological data where the bridge is located: the weather conditions, wind direction, maximum temperature, and minimum temperature both during the day and at night. 


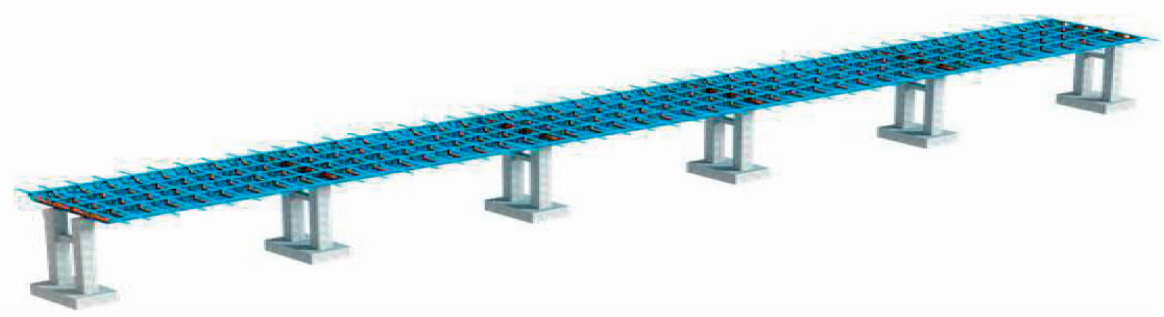

Figure 1: Structural layout of the fifth steel beam.

\begin{tabular}{|c|c|c|c|c|c|c|c|c|}
\hline 2 & $\mathrm{C} 2$ & $\mathrm{C} 2$ & $\mathrm{C} 1$ & C1 & $\mathrm{C}_{1}$ & $\mathrm{C} 2$ & $\mathrm{C} 2$ & B2 \\
\hline E2 & $F 2$ & F2 & F1 & F1 & F1 & F2 & F2 & E2 \\
\hline $\mathrm{H} 2$ & 12 & 12 & 11 & 11 & 11 & 12 & 12 & $\mathrm{H} 2$ \\
\hline $\mathrm{H} 2$ & 12 & 12 & 11 & 11 & 11 & 12 & 12 & 12 \\
\hline E2 & $F 2$ & $F 2$ & F1 & F1 & F1 & F2 & $\mathrm{F} 2$ & E2 \\
\hline B2 & $\mathrm{C} 2$ & $\mathrm{C2}$ & C1 & C1 & C1 & $\mathrm{C} 2$ & $\mathrm{C2}$ & B2 \\
\hline \multicolumn{9}{|c|}{35000} \\
\hline
\end{tabular}

Center line of pier

Center line of pier

Figure 2: Structural plan of the bridge deck (unit: $\mathrm{m}$ ).

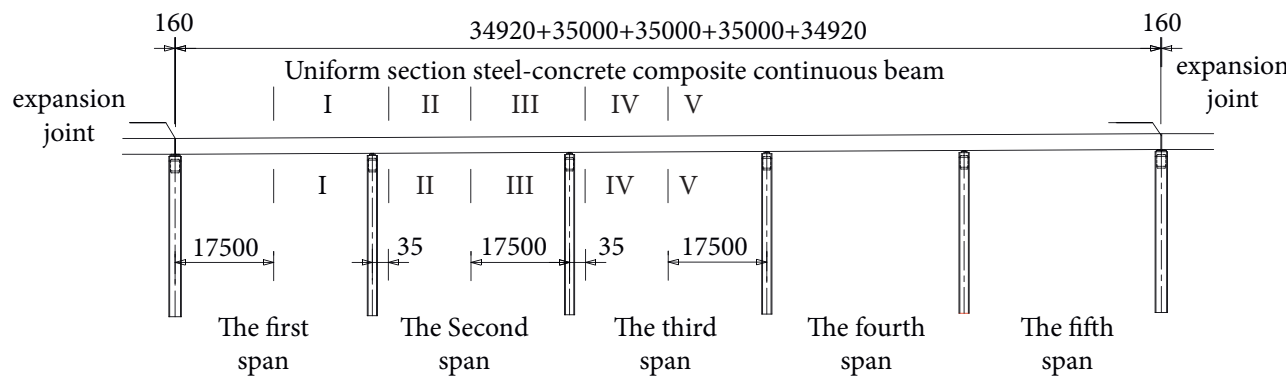

FIgURE 3: Location of the test section (unit: $\mathrm{mm}$ ).

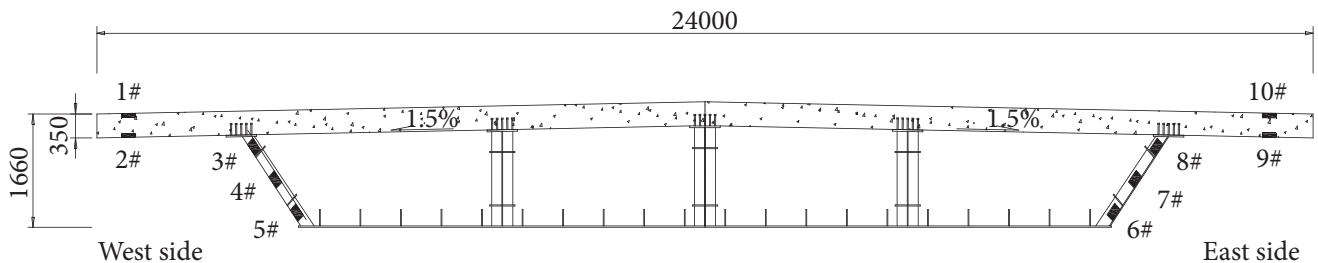

FIGURE 4: Layout of section measuring points (unit: $\mathrm{mm}$ ).

TABLe 1: Meteorological data record.

\begin{tabular}{|c|c|c|c|c|c|c|}
\hline \multirow[b]{2}{*}{ Date } & \multicolumn{3}{|c|}{ Day } & \multicolumn{3}{|c|}{ Night } \\
\hline & Condition & Wind direction & $\begin{array}{c}\text { Maximum } \\
\text { temperature }\left({ }^{\circ} \mathrm{C}\right)\end{array}$ & Condition & $\begin{array}{c}\text { Wind } \\
\text { direction }\end{array}$ & $\begin{array}{c}\text { Minimum } \\
\text { temperature }\left({ }^{\circ} \mathrm{C}\right)\end{array}$ \\
\hline 2021-06-06 & Cloudy & North wind $\leq 3$ & 26 & Cloudy & North wind $\leq 3$ & 15 \\
\hline 2021-06-07 & Sunny & North wind $\leq 3$ & 32 & Cloudy & North wind $\leq 3$ & 18 \\
\hline 2021-06-08 & Cloudy & North wind $\leq 3$ & 28 & Sunny & North wind $\leq 3$ & 18 \\
\hline 2021-06-09 & Sunny & North wind $\leq 3$ & 32 & Cloudy & North wind $\leq 3$ & 20 \\
\hline 2021-06-10 & Cloudy & North wind $\leq 3$ & 32 & Cloudy & North wind $\leq 3$ & 20 \\
\hline 2021-06-11 & Sunny & North wind $\leq 3$ & 32 & Cloudy & North wind $\leq 3$ & 19 \\
\hline
\end{tabular}




\section{Results and Discussion}

3.1. Establishment of a Finite Element Model. In this paper, the fifth section of the viaduct is selected as a case study. The $35 \mathrm{~m}$ box composite box girder bridge is modelled and analysed by using the finite element software midas Civil. According to the design drawings and the defined construction stage, the steel box girder and concrete deck are simulated by using beam elements. The whole bridge is divided into 121 nodes, 120 elements, and 16 boundary conditions (including permanent piers and auxiliary piers). The steel-concrete composite section is simulated by the joint section in the construction stage. Considering the construction temporary load, the self-weight coefficient is 1.1 , and the second phase dead load is $20 \mathrm{kN} / \mathrm{m}$.

According to the most unfavourable temperature gradient rise and drop curve, the temperature difference of the box composite beam section presents a nonlinear distribution, and the linear expansion coefficient and elastic modulus of the steel box girder and concrete bridge deck are not the same. Therefore, the loading mode of "beam section temperature" is adopted instead of "temperature gradient" in the software. The temperature distribution in the composite beam section can be more accurately simulated by inputting the temperature values of different positions along the beam height direction. The overall calculation model is shown in Figure 5.

The influence of the temperature gradient causes thermal deformation of the bridge. When the deformation is hindered by the internal and external constraints of the structure, thermal stress is generated. Due to the good thermal conductivity, large temperature expansion coefficient, and sensitivity to temperature change of steel, the temperature distribution of the steel beam section is complex under the influence of the temperature difference, and the geometric alignment and internal force state of the bridge structure are closely related to the temperature change. Therefore, its influence must be fully considered.

\subsection{Integral Temperature Field of the Composite Box Girder} Bridge. Since the temperatures of the corresponding measuring points of different test sections are similar, this paper lists the measured temperature data of each measuring point of only the second midspan section at different times, as shown in Tables 2 and 3. The temperatures at different times are connected with a smooth curve to form a temperature time history curve, as shown in Figures 6 and 7.

The following can be concluded from the representative two-day overall temperature field of the east and west cross sections:

(1) The temperature of the measuring point in the concrete bridge deck changes gradually with the change in the ambient temperature. Due to its thermal inertia, there is a certain lag phenomenon relative to the atmospheric temperature. The sunrise time is $05: 16$. The temperature of the concrete bridge deck gradually rises and approaches the ambient temperature. The main heating process occurs after 06:00. As the temperature continues to rise, the main heat exchange in this period comes from the solar radiation heat. The maximum temperature difference between the bridge deck and the ambient temperature is $4.9^{\circ} \mathrm{C}$. The sunset time is $19: 52$, and the atmospheric temperature decreases rapidly, but in the early cooling stage, the temperature of the bridge deck is still higher than the ambient temperature, and the bridge structure begins to dissipate the heat absorbed in the daytime to the environment, which is basically the same as the ambient temperature at $22: 30$ at night and gradually becomes lower than the ambient temperature.

(2) Because the upper surface of the concrete bridge deck is directly exposed to sunlight, the temperature rise of the corresponding measuring points is faster, while the measuring points on the lower surface are not directly exposed to sunlight, and the temperature rise is relatively slow. During the period of $07: 00-21: 00$, the temperature difference between the upper and lower surfaces gradually increases, and the maximum temperature difference reaches $4.6^{\circ} \mathrm{C}$. After the temperature difference reaches this extreme value, it gradually decreases.

(3) The heating process of the steel box girder is faster than that of the concrete. However, due to the long cantilever of the bridge deck, the steel box girder is shielded to a certain extent. Therefore, among the three main heat sources of direct sunlight radiation, atmospheric temperature transfer, and concrete bridge deck temperature transfer, the influence time of sunlight radiation is shorter. The temperature change in the steel beam is mainly affected by the environmental temperature and the temperature transfer of other structures from high to low. Because the upper measuring points (\#3 and \#8) of the two webs cannot accept solar radiation all the time, the temperature change range is small, and the heating and cooling rates of the corresponding measuring points are lower than those of the other measuring points. The temperature of each measuring point of the box beam structure increases gradually at first, reaches the maximum at 17:00, and then decreases slowly.

(4) The bridge structure has a north-south alignment, and the sunshine in the morning comes from the northeast. A comparison of the data measured from the abovementioned two days indicates that the temperature of the east measuring point is generally higher than that of the west measuring point, and the maximum temperature difference between the east 


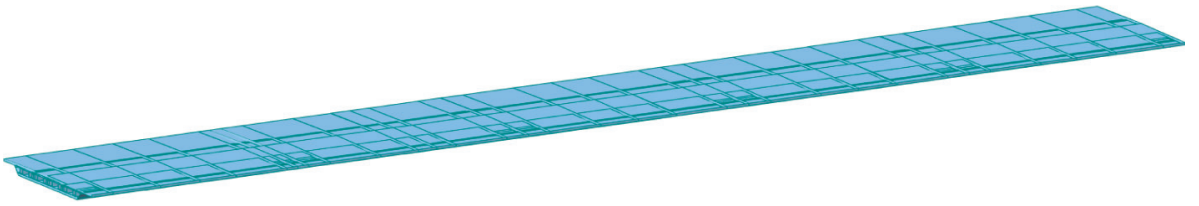

FIGURE 5: Steel-concrete composite bridge structure model.

TABle 2: Temperature data measured on June 7, 2021 (unit: ${ }^{\circ} \mathrm{C}$ ).

\begin{tabular}{|c|c|c|c|c|c|c|c|c|c|c|c|}
\hline Time & Ambient temperature & $\# 1$ & $\# 2$ & $\# 3$ & $\# 4$ & $\# 5$ & $\# 6$ & $\# 7$ & $\# 8$ & $\# 9$ & $\# 10$ \\
\hline $01: 00$ & 20 & 18.6 & 19.7 & 19.5 & 19.9 & 20 & 18.3 & 18.6 & 19.1 & 19.6 & 19.1 \\
\hline $03: 00$ & 18 & 16.9 & 17.6 & 17.2 & 16.9 & 16.8 & 16.5 & 16.8 & 17.1 & 17.3 & 17.2 \\
\hline $05: 00$ & 18 & 16.2 & 17.1 & 16.9 & 16.8 & 16.9 & 16.4 & 16.7 & 16.7 & 16.8 & 16.9 \\
\hline $07: 00$ & 19 & 17.8 & 17.3 & 18.6 & 18.8 & 18.7 & 20.8 & 21.2 & 20.3 & 19.5 & 20.1 \\
\hline 09:00 & 22 & 23.2 & 20.9 & 21.6 & 22 & 21.8 & 24.5 & 24.8 & 23.9 & 23.1 & 23.8 \\
\hline $11: 00$ & 26 & 27.8 & 23.4 & 25.2 & 25.6 & 25.5 & 29.6 & 29.8 & 28.7 & 27.1 & 27.9 \\
\hline $13: 00$ & 29 & 32.1 & 28.1 & 28.6 & 29.2 & 28.9 & 30.1 & 30.5 & 29.8 & 29.5 & 32.3 \\
\hline $15: 00$ & 31 & 33.5 & 31.9 & 32.6 & 34.2 & 34.1 & 30.6 & 30.8 & 30.5 & 30.9 & 33.1 \\
\hline $17: 00$ & 32 & 33.8 & 32.5 & 32.9 & 34.9 & 34.5 & 32.1 & 32.3 & 31.5 & 31.1 & 33.3 \\
\hline $19: 00$ & 30 & 32.9 & 32.1 & 31.1 & 31.6 & 31.3 & 30.2 & 30.3 & 30.1 & 30.7 & 31.3 \\
\hline $21: 00$ & 23 & 27.5 & 26.8 & 24.7 & 24.7 & 24.5 & 22.9 & 23.3 & 23.1 & 25.6 & 26.8 \\
\hline $23: 00$ & 21 & 21.1 & 21.9 & 20.2 & 20.4 & 20.4 & 20.4 & 20.5 & 20.2 & 20.8 & 20.3 \\
\hline
\end{tabular}

Table 3: Temperature data measured on June 11, 2021 (unit: ${ }^{\circ} \mathrm{C}$ ).

\begin{tabular}{|c|c|c|c|c|c|c|c|c|c|c|c|}
\hline Time & Ambient temperature & $\# 1$ & $\# 2$ & $\# 3$ & $\# 4$ & $\# 5$ & $\# 6$ & $\# 7$ & $\# 8$ & $\# 9$ & $\# 10$ \\
\hline $01: 00$ & 21 & 18.9 & 20.7 & 19.7 & 19.5 & 19.6 & 19.5 & 19.6 & 19.8 & 20.5 & 19.1 \\
\hline $03: 00$ & 19 & 18.1 & 19.3 & 18.5 & 18.4 & 18.5 & 18.2 & 18.4 & 18.5 & 19.6 & 18.1 \\
\hline $05: 00$ & 20 & 18.7 & 19.4 & 18.7 & 18.5 & 18.6 & 18.4 & 18.5 & 18.6 & 18.8 & 18.3 \\
\hline $07: 00$ & 24 & 23.9 & 21.3 & 22.6 & 22.7 & 22.4 & 23.4 & 23.9 & 23.1 & 23.8 & 25.4 \\
\hline 09:00 & 26 & 28.7 & 24.3 & 26.1 & 26.8 & 26.5 & 28.2 & 28.8 & 27.9 & 27.2 & 29.6 \\
\hline $11: 00$ & 27 & 31.9 & 27.3 & 27.4 & 27.7 & 27.5 & 31.7 & 32.9 & 31.1 & 30.2 & 32.2 \\
\hline $13: 00$ & 31 & 33.7 & 31.1 & 30.2 & 31.3 & 30.8 & 32.5 & 33.1 & 31.8 & 31 & 34.1 \\
\hline $15: 00$ & 31 & 34.9 & 31.5 & 31.7 & 32.8 & 32.3 & 32.2 & 32.9 & 32.1 & 31.5 & 35.2 \\
\hline $17: 00$ & 32 & 35.7 & 32.6 & 32.8 & 33.6 & 32.9 & 32.7 & 33.1 & 32.2 & 31.8 & 35.8 \\
\hline $19: 00$ & 31 & 35.3 & 32.3 & 31.2 & 31.8 & 31.6 & 30.6 & 30.8 & 30.5 & 31.3 & 34.8 \\
\hline $21: 00$ & 28 & 30.5 & 29.6 & 29.4 & 28.7 & 28.5 & 28.4 & 28.6 & 28.2 & 29.2 & 29.5 \\
\hline $23: 00$ & 27 & 28.8 & 28.3 & 27.4 & 27.5 & 27.1 & 26.5 & 26.8 & 26.7 & 27.8 & 27.2 \\
\hline
\end{tabular}

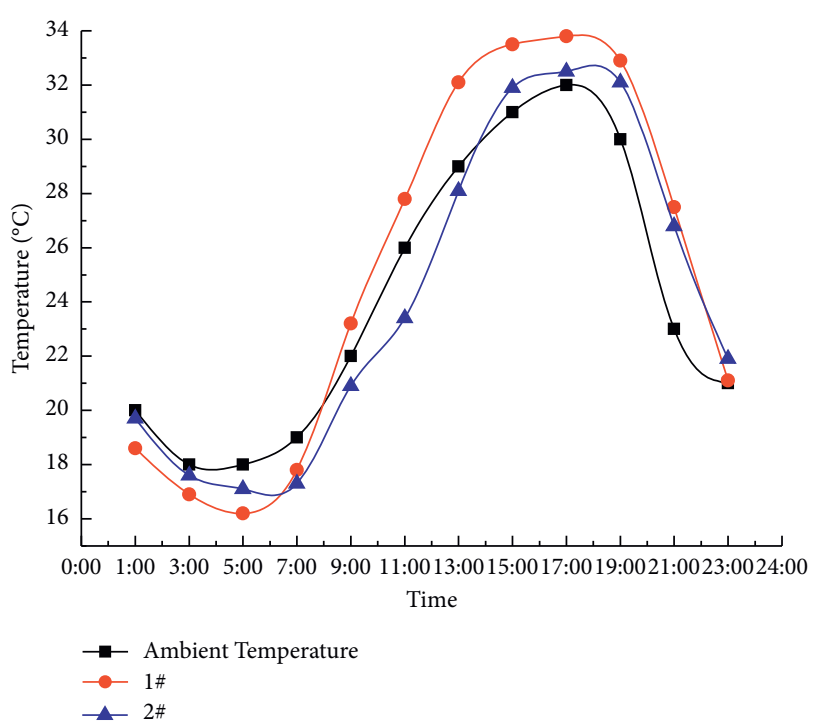

(a)

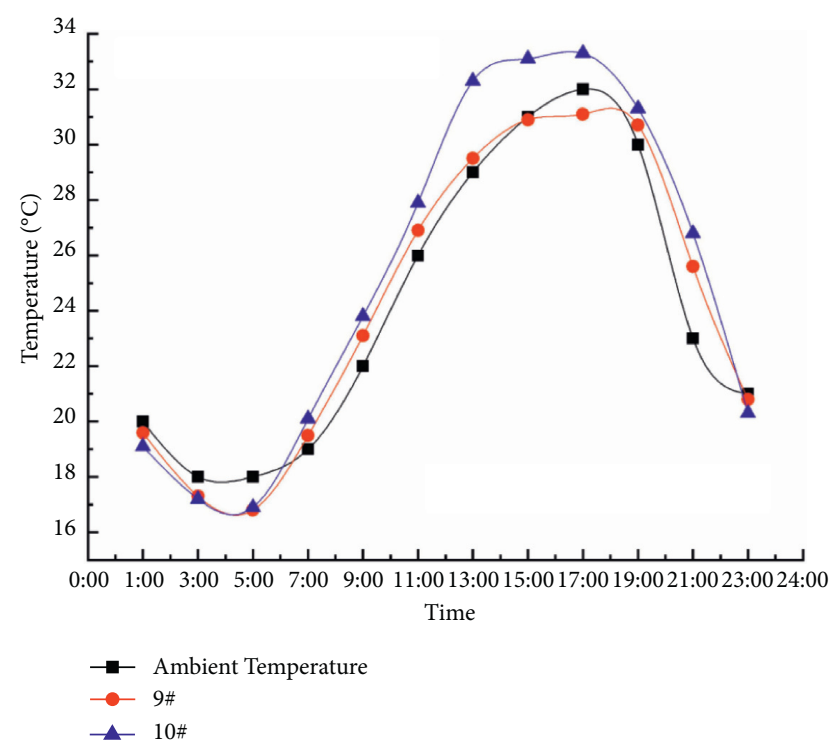

(b)

FIGURE 6: Continued. 


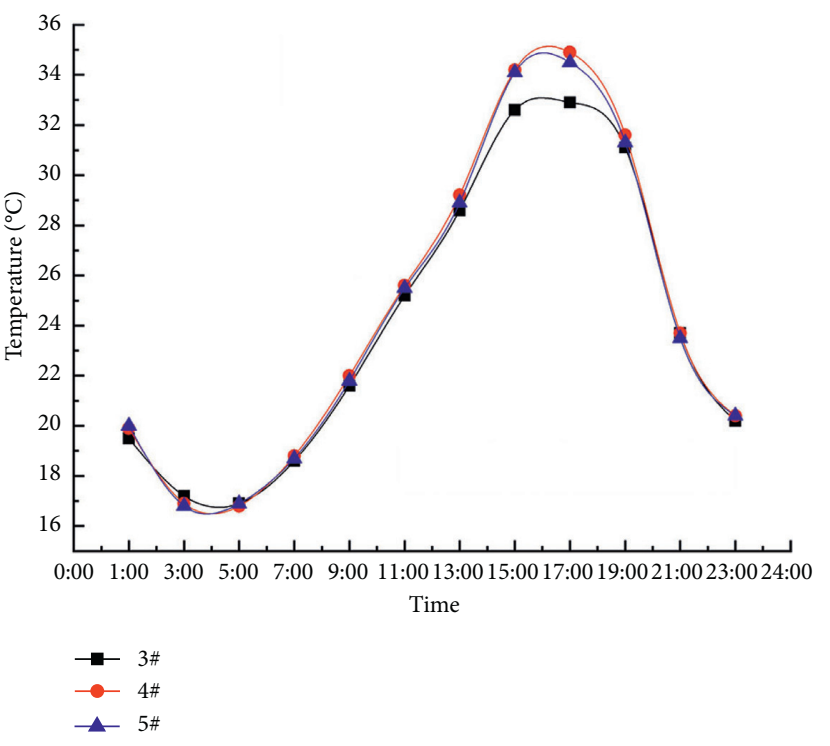

(c)

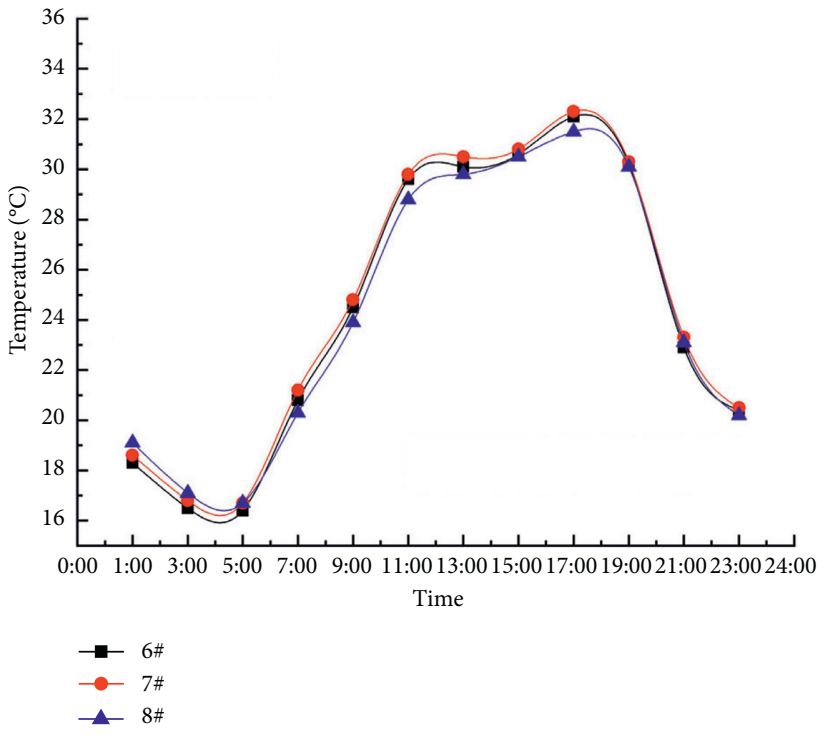

(d)

Figure 6: Curves of ambient temperature with time on June 6, 2021, at different measuring points. (a) Ambient temperature, measuring point \#1 and measuring point \#2. (b) Ambient temperature, measuring point \#9 and measuring point \#10. (c) Measuring points \#3, \# 4, and \#5. (d) Measuring points \#6, \#6, and \#8.

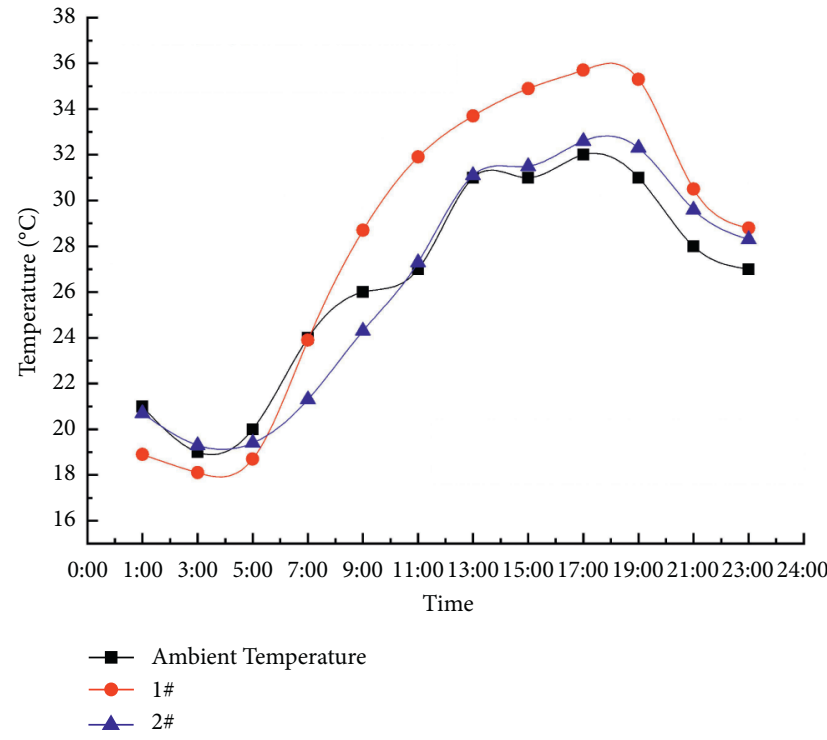

(a)

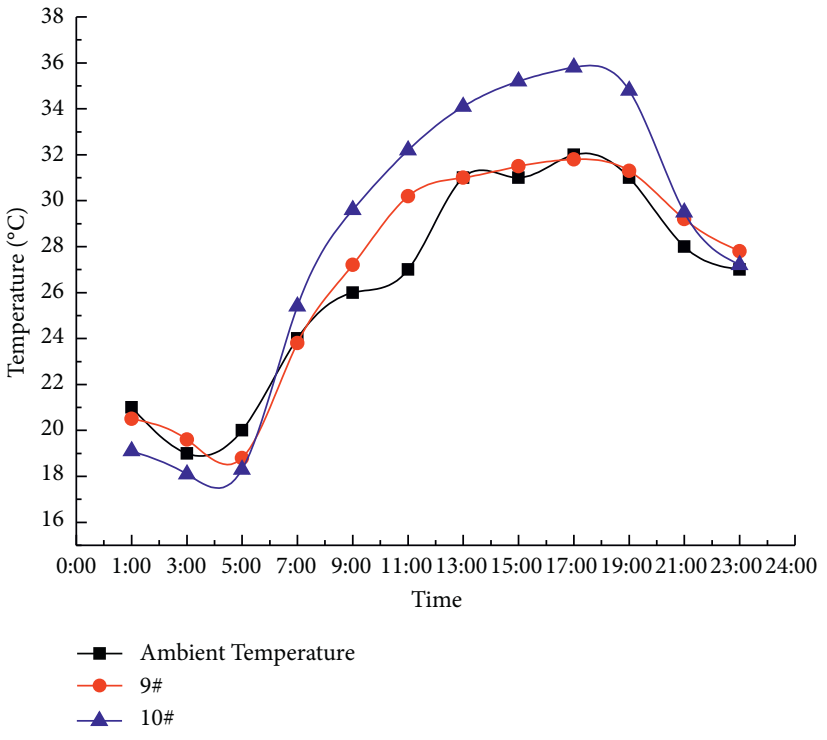

(b)

Figure 7: Continued. 


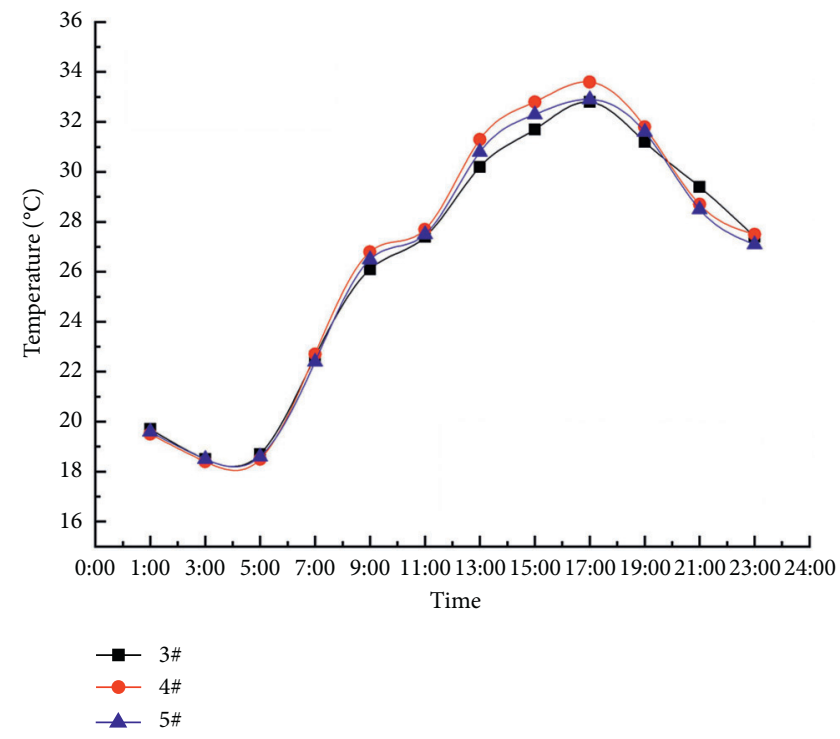

(c)

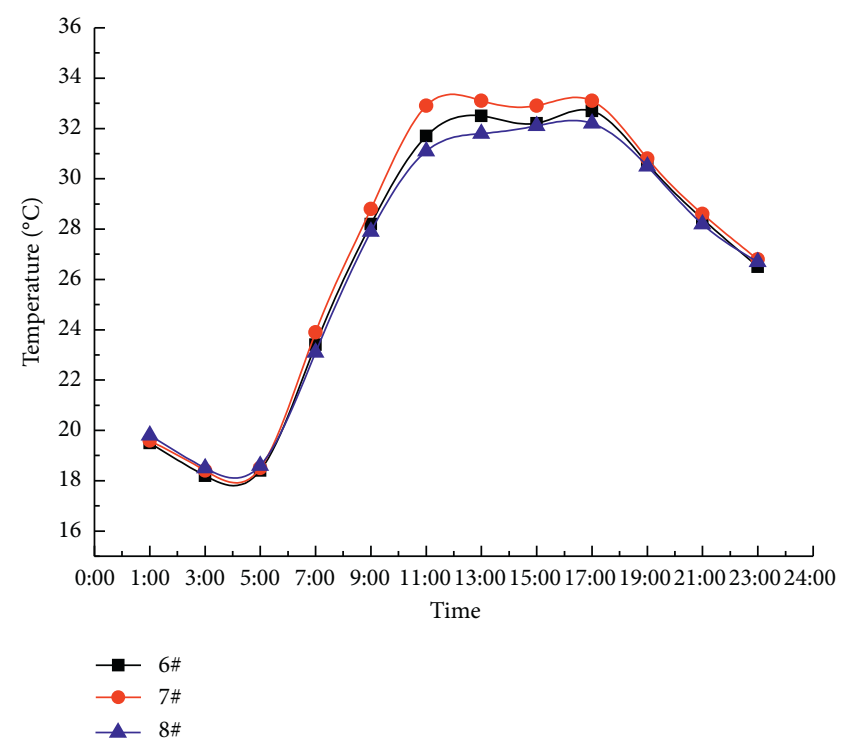

(d)

Figure 7: Curves of measuring points and ambient temperature with time on June 11, 2021. (a) Ambient temperature, measuring point \#1 and measuring point \#2. (b) Ambient temperature, measuring point \#9 and measuring point \#10. (c) Measuring points \#3, \# 4, and \#5. (d) Measuring points \#6, \#7, and \#8.

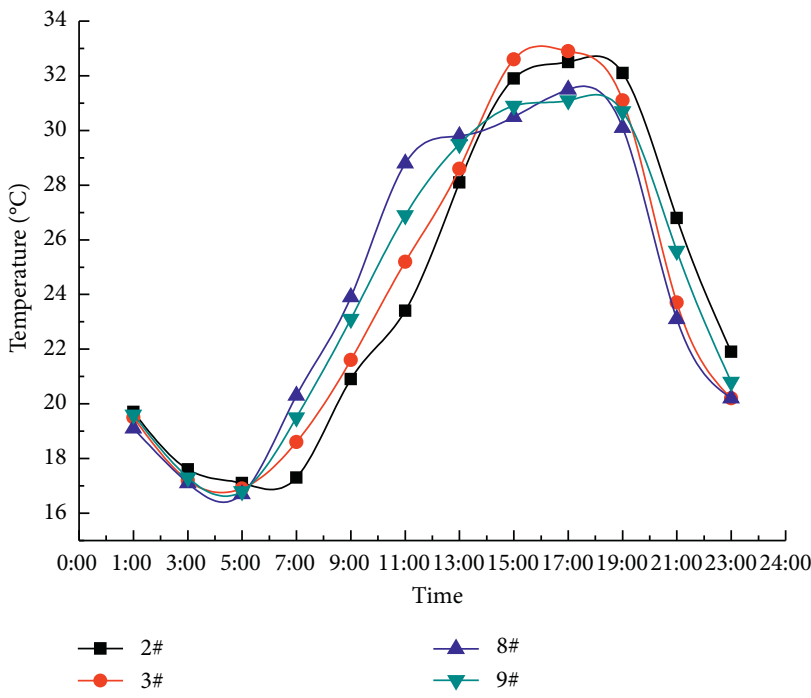

(a)

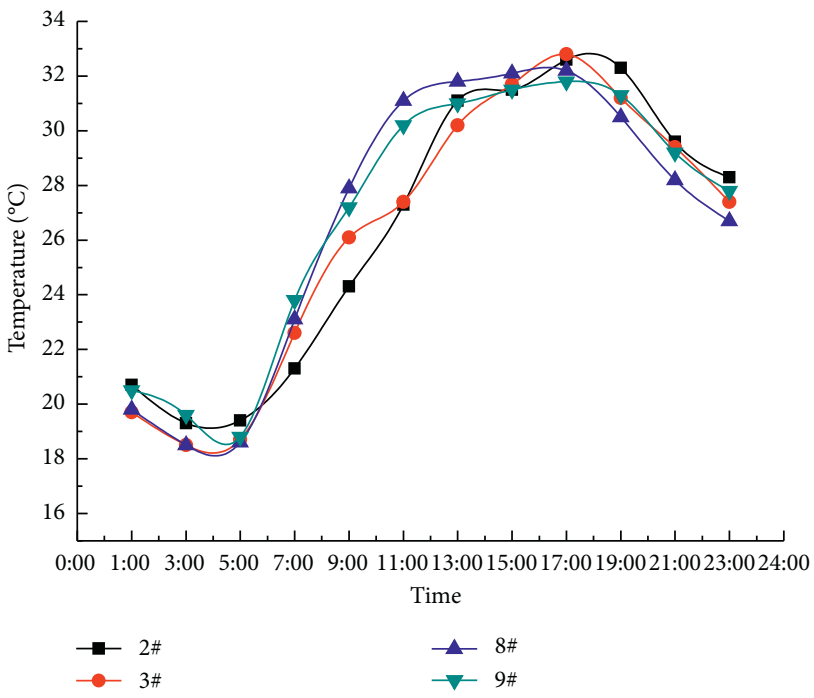

(b)

Figure 8: Curves of measuring points and ambient temperature with time. (a) Local temperature field on June 7. (b) Local temperature field on June 11.

and west sides occurs at $11: 00$ on June 11 . At this time, the difference between measuring point \#7 on the east side of the steel beam and measuring point \#4 on the corresponding west side is the largest, which is $5.2^{\circ} \mathrm{C}$, indicating that in the process of a gradual increase in atmospheric temperature, the temperature change in the bridge structure is mainly affected by solar radiation, so the temperature of the east measuring point is generally higher than that of the west measuring point. In the afternoon, when the sunshine location is in the northwest, the temperature of the west measuring point begins to rise, but in the sunshine period, the maximum temperature difference between the east and west sides of the bridge structure is $3.5^{\circ} \mathrm{C}$, which is significantly lower than the maximum temperature difference in the morning. Theoretically, when the sun moves westward, in the afternoon, the west side of the bridge structure has a longer sunshine time and absorbs more solar radiation heat than the east side. 
However, the actual data are not consistent with the theoretical analysis, which shows that with the increase in atmospheric temperature, the influence of sunshine radiation on the bridge structure temperature decreases, and its temperature change is due to mainly the heat transfer of the surrounding environment.

(5) According to the measured data, the maximum temperature difference at the same measuring point of the bridge structure in one day is $17.7^{\circ} \mathrm{C}$, which occurs at the measuring point of the box girder structure corresponding to the maximum observed temperature. Based on the analysis of the influencing factors of the temperature field distribution of the composite box girder bridge structure, it is concluded that the influence of the temperature field on the concrete slab and the steel box girder is not uniform. For the concrete slab, the sunlight radiation intensity and direction are the key factors. For the steel box girder, the change in the ambient temperature and the heat transfer between the structures are the main factors.

\subsection{Local Temperature Field of the Composite Box Girder} Bridge. In the actual monitoring process of the bridge, the local temperature field of the steel-concrete composite beam is shown at the junction of the concrete slab and the steel beam. The layout of the measuring points on-site indicates that the results can be obtained by comparing the temperature difference between measuring points \#2 and \#3 and measuring points \#8 and \#9 at the same time. The specific temperature comparison is shown in Figure 8.

The following can be concluded from the representative two-day local temperature fields of the east and west sides of the cross section:

(1) By analysing the temperature change curve of each moment in the diagram, it can be concluded that the lower surface of the concrete bridge deck is close to the upper measuring point of the steel beam web. The upper part of the steel beam web is not directly illuminated by the sun due to the shielding of the cantilever of the concrete bridge deck, and its temperature change mainly comes from the influence of the surrounding environment and the heat conduction of the bridge structure. There is a certain degree of temperature difference in the local range of this junction. The temperature difference between points \#2 and \#3 on the west side is relatively large, and the maximum temperature difference can reach $2.1^{\circ} \mathrm{C}$. The temperature difference between points $\# 8$ and $\# 9$ on the east side is relatively small, and the maximum temperature difference is $1.6^{\circ} \mathrm{C}$.

(2) During the gradual increase in atmospheric temperature, the heat conduction speed of the steel beam is faster than that of the concrete bridge deck, which is relatively slow. Therefore, the temperature of the upper part of the steel beam web at the structural connection is higher than that of the lower surface of the concrete bridge deck. With the continuous increase in temperature, when the structural temperature reaches the maximum, the temperature of the concrete slab is close to that of the steel beam. The temperature of the concrete slab is higher than that of the steel beam because the temperature of the concrete slab considerably lags behind that of the atmosphere, and the temperature of the concrete slab is higher than that of the steel beam until approximately 18:00. The temperature of the concrete slab is basically consistent, and the temperature of the steel beam is higher than that of the steel beam. Most of the time, due to the heat transfer between the joint of the concrete slab and the steel beam structure, although there is a certain degree of temperature difference in the joint of the structure, the difference is not large.

3.4. Determination of the Vertical Temperature Gradient of the Cross Section. In the design of steel-concrete composite bridges, the temperature gradient is mainly determined according to the specifications, but it is not completely applicable to the actual temperature difference in different areas. Therefore, it is very important to determine the vertical temperature gradient of real bridge sections, which can provide a reference for the design of local bridges in the future. Analysis of the measured data indicates that the factors affecting the temperature change in the whole viaduct section of Binhe West Road are very complex, the temperature changes among the measuring points of the section are not uniform with time, and the vertical temperature gradient varies at different times and different spatial positions.

The temperature gradient of the vertical section of the steel-concrete composite bridge structure is divided into a heating gradient and a cooling gradient. Previous studies have considered that the temperature change in the cooling gradient section is small, so this change is often ignored. In this paper, two representative days are selected to compare the heating and cooling gradient modes of the eastern and western sections, as shown in Figure 9.

The following can be concluded from the vertical temperature gradient diagram of the section at each moment:

(1) The height of the concrete deck of this bridge is $350 \mathrm{~mm}$. Although the height is small, the temperature difference between the upper and lower surfaces of the east and west sides of the deck is still prominent, especially on June 11.

(2) The vertical temperature difference of the steel beam section is smaller than that of the upper and lower surface of the concrete bridge deck, and its temperature distribution law is as follows. In the heating stage, most of the time, the temperature of the upper part of the web is the lowest, that of the lower part is 


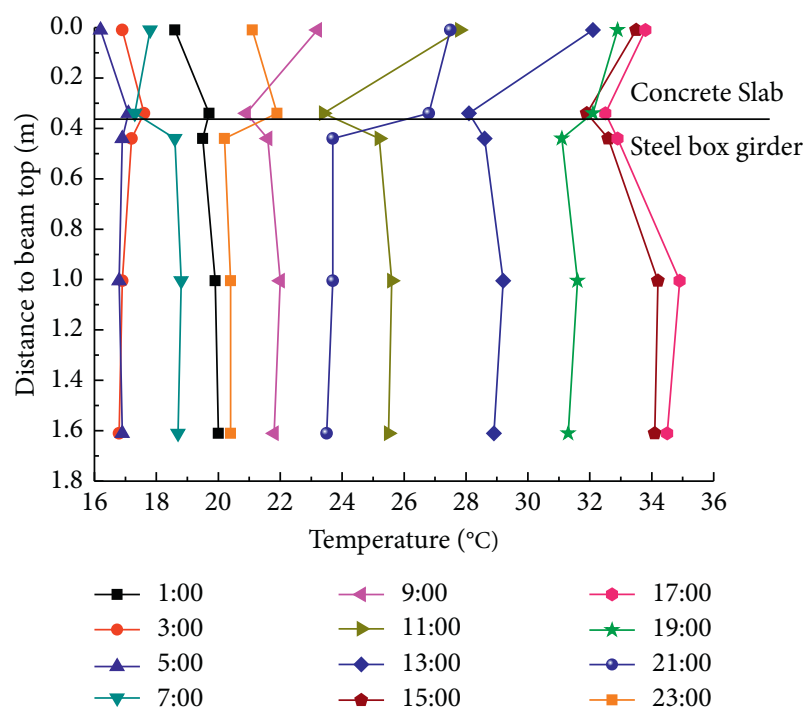

(a)

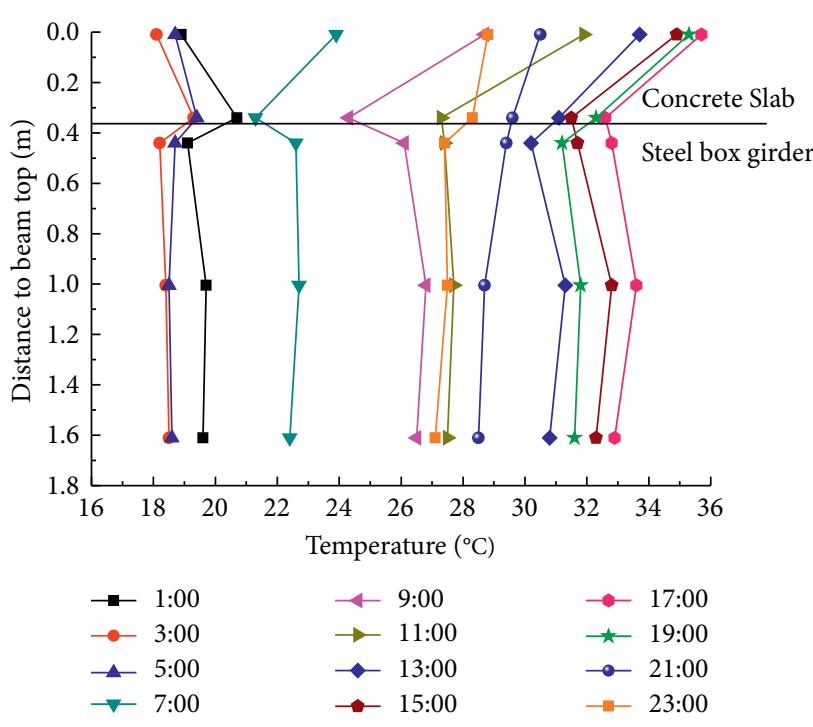

(c)

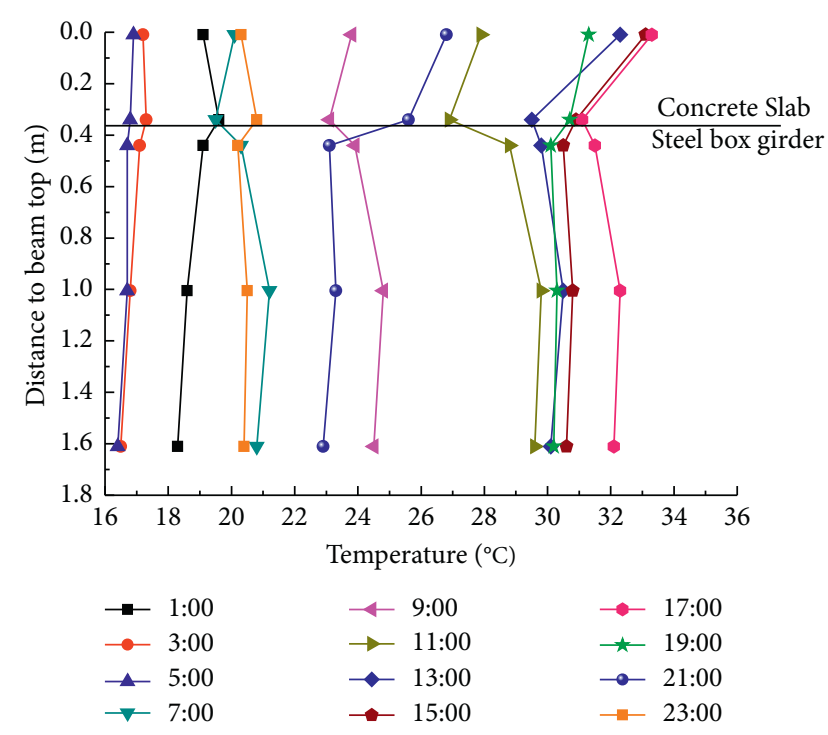

(b)

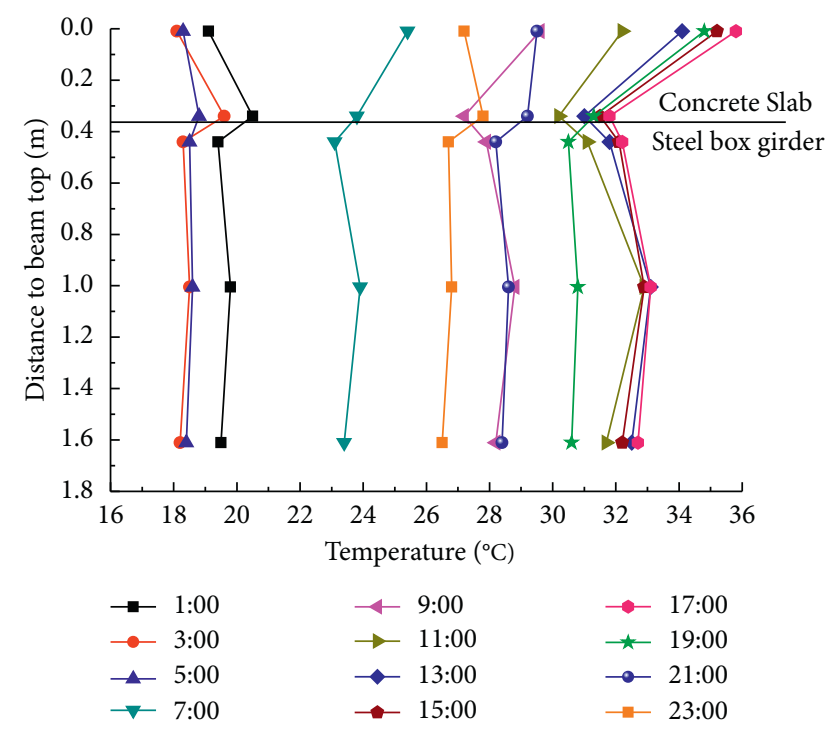

(d)

FIgURE 9: Curves of the temperature gradient on the vertical section. (a) West section on June 7. (b) East section on June 7. (c) West section on June 11. (d) East section on June 11.

the second lowest, and that of the middle part is the highest. However, in the cooling stage, most of the time, the temperature of the lower part of the web is the lowest, that of the middle part is the second lowest, and that of the upper part is the highest. This distribution law clearly applies to both the east and west sides of the steel box girder.

To obtain the time when the most unfavourable temperature gradient may appear within 24 hours, it is necessary to analyse the vertical temperature gradient of steel-concrete composite bridge sections according to different methods to find the optimal solution.

According to past experience and the analysis of the measured data, at approximately 17:00, the surface temperature of the concrete bridge deck reaches the maximum, and it is also the time when the vertical temperature difference of the structure reaches the maximum. If we simply select this time as the most unfavourable temperature gradient distribution, this method is easy to use, but it cannot completely match the actual situation.

Another method used to determine the most unfavourable vertical temperature gradient is to select the temperature distribution when the thermal stress of the upper and lower edges of the section reaches the maximum at the same time. However, according to the site conditions, the thermal stress of the bridge cannot be measured. When the bottom deflection of the steel box girder is the maximum, the thermal stress of the lower edge is the maximum, and the temperature of the upper edge of the 


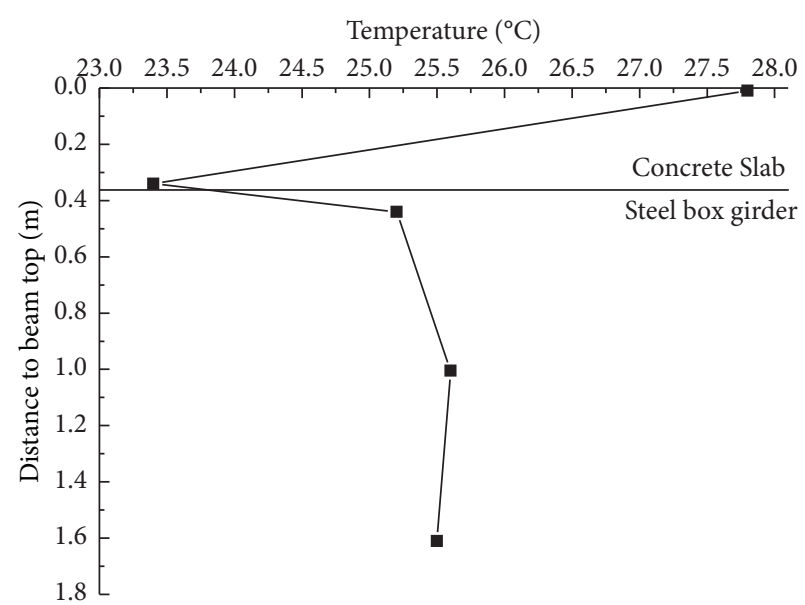

(a)

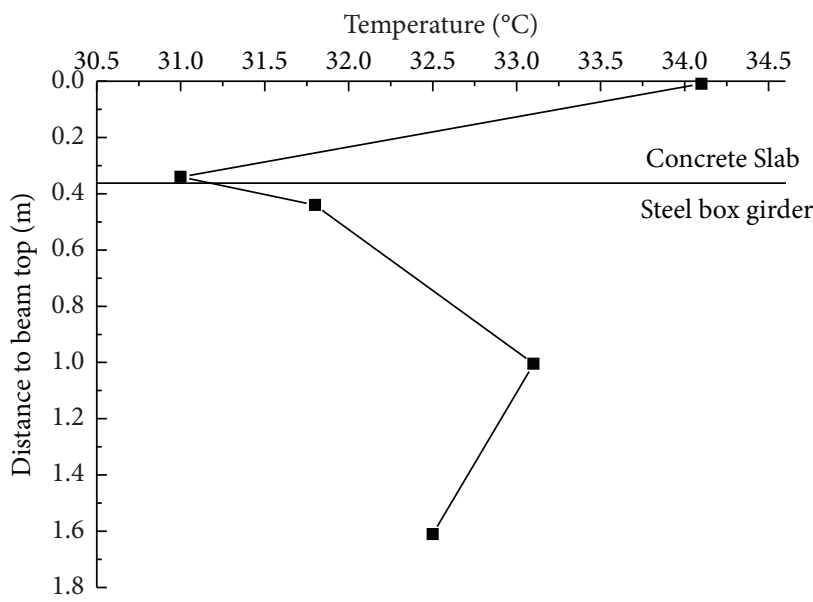

(c)

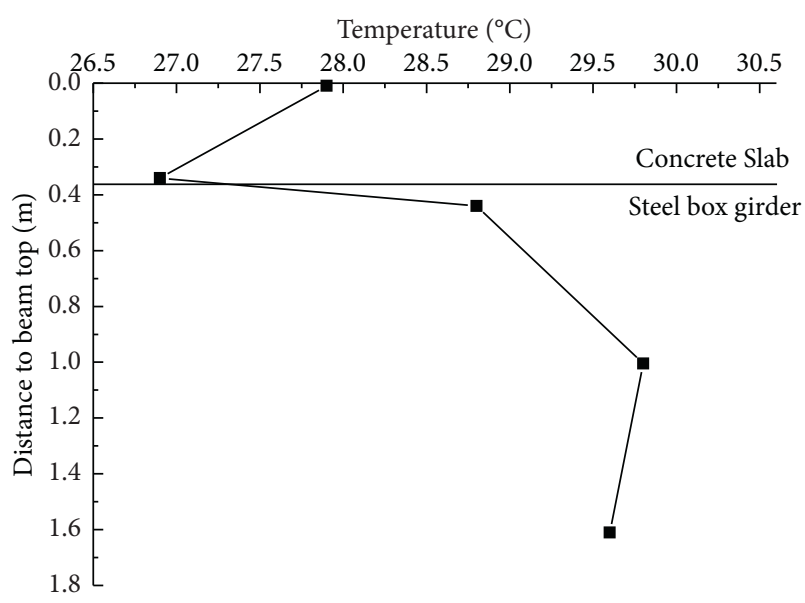

(b)

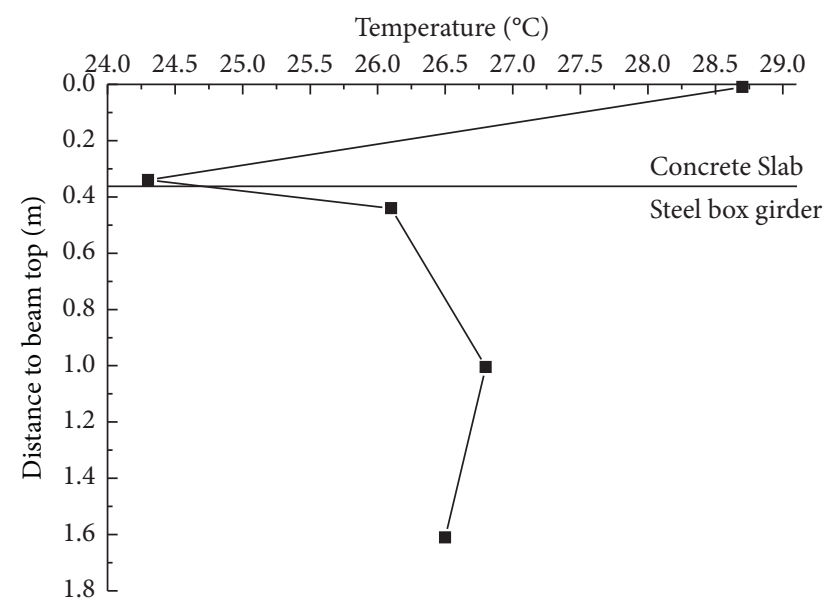

(d)

Figure 10: Most unfavourable curves of the temperature rise gradient on the vertical section. (a) West section on June 7. (b) East section on June 7. (c) West section on June 10. (d) East section on June 10.

concrete deck is the maximum. Because the times when the thermal stress of the upper and lower edges of the bridge reaches the maximum are not synchronous, this method is not feasible.

In this paper, the minimum temperature change point within 24 hours is used as the reference point to calculate the temperature difference between the other measuring points and the reference point at each time of the section, and the temperature distribution of the vertical section at the difference and the maximum time is selected as the most unfavourable temperature gradient. The time distance is relatively long, and the temperature difference between the cross-section measuring point and the reference point at the maximum time is likely to appear between any observation time in a day. To obtain the most unfavourable temperature gradient accurately, 48 measurements are obtained within the 24 hours of a day, at an interval of 0.5 hour. The temperature difference and magnitude at each time are compared, and the maximum temperature difference and temperature distribution are selected as the most unfavourable vertical temperature gradients. According to the conditions of the east and west sides and the two-day temperature rise and drop, the most unfavourable temperature gradient distribution of eight groups of vertical sections is obtained, as shown in Figures 10 and 11.

The above eight groups of fitted most unfavourable temperature gradients are averaged according to the rising and falling temperatures. Finally, the two groups of most unfavourable temperature gradient distribution maps are obtained, as shown in Figure 12.

According to the conclusion, there is a certain degree of temperature difference in the local temperature field at the joint of the steel-concrete composite beam, so the temperature gradients in the concrete deck and the steel box girder are fitted separately. According to previous research experience and the characteristics of the small thickness of the concrete deck of this bridge, the temperature gradient in the concrete slab is fitted according to a linear function distribution. The distribution mode of the temperature gradient in the steel box girder is based on the lower surface of the concrete bridge deck $(y=0.35 \mathrm{~m})$. The least square method is used to fit the distribution mode, and MATLAB is used to calculate the analysis function formula. It is 

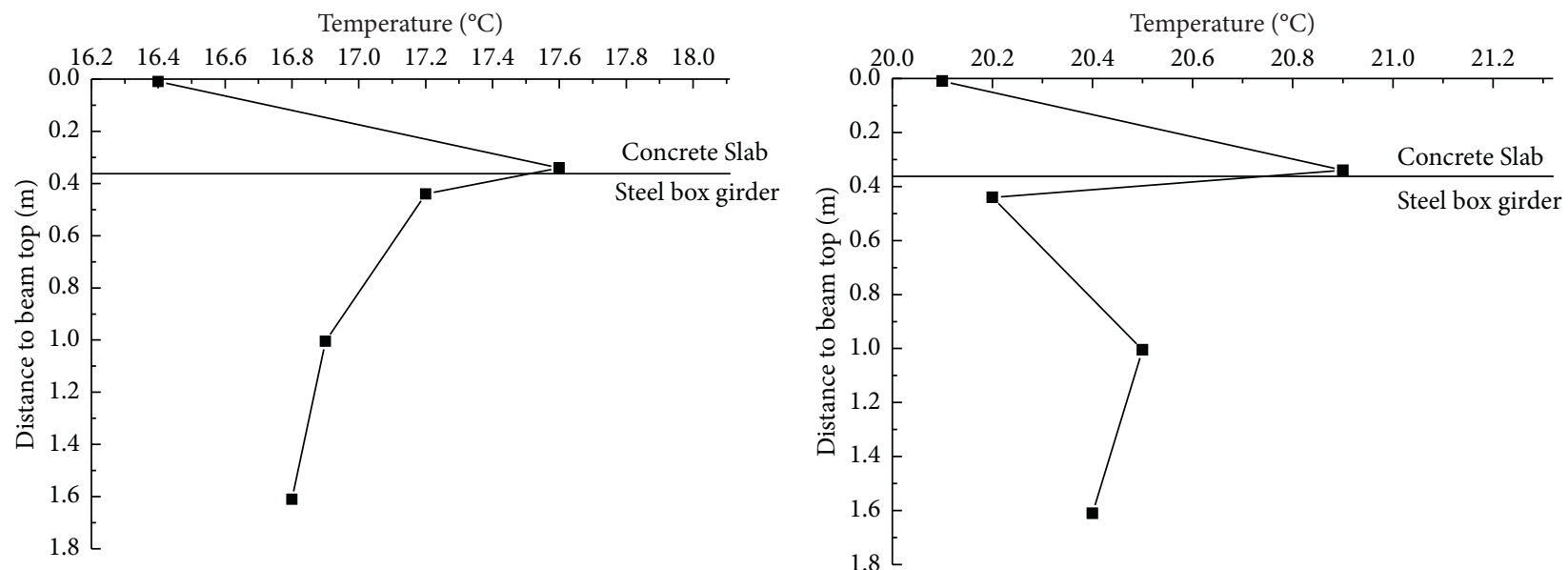

(a)

(b)

Temperature $\left({ }^{\circ} \mathrm{C}\right)$

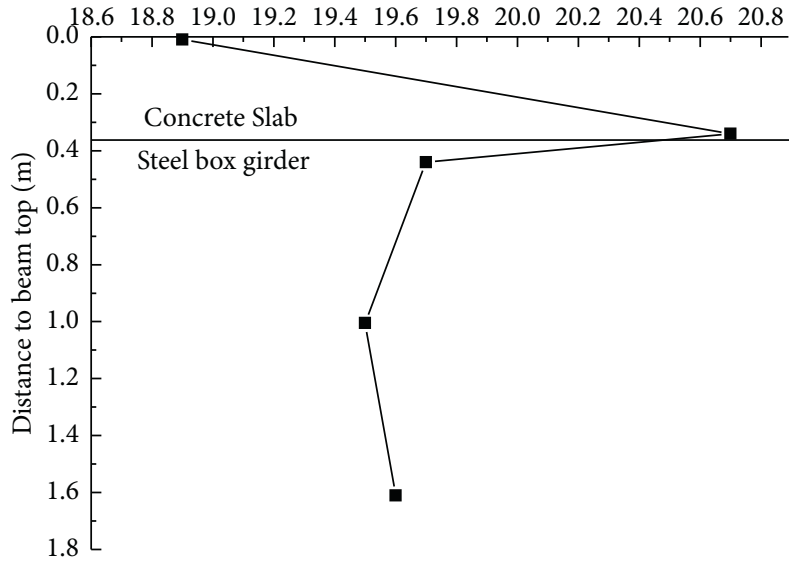

(c)

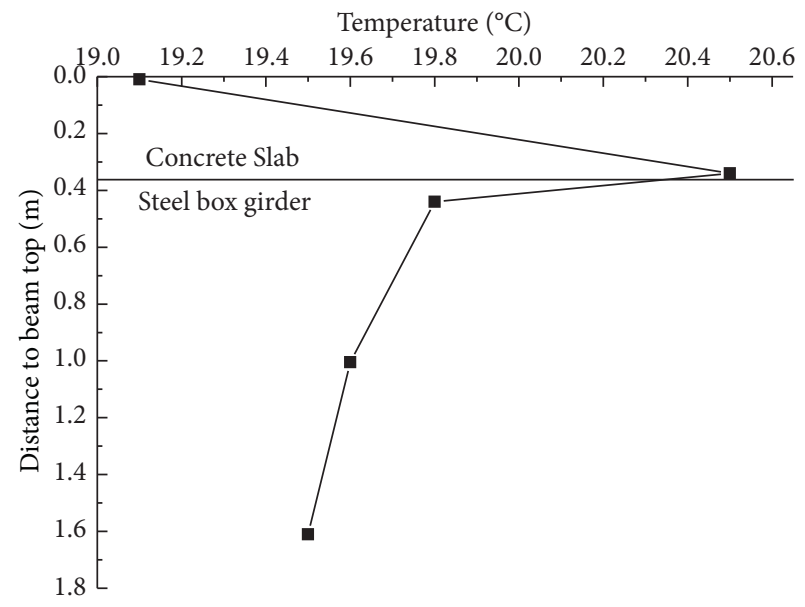

(d)

Figure 11: Most unfavourable curves of the temperature drop gradient on the vertical section. (a) West section on June 7. (b) East section on June 7. (c) West section on June 11. (d) East section on June 11.

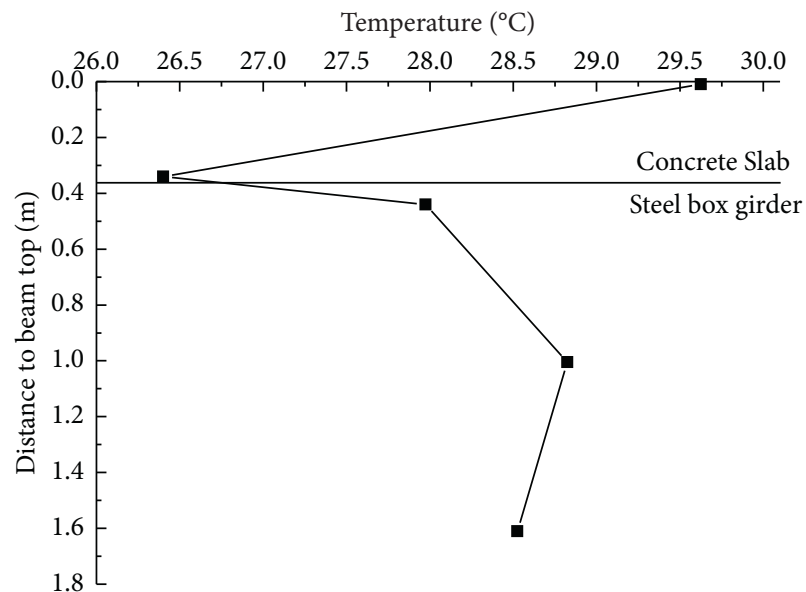

(a)

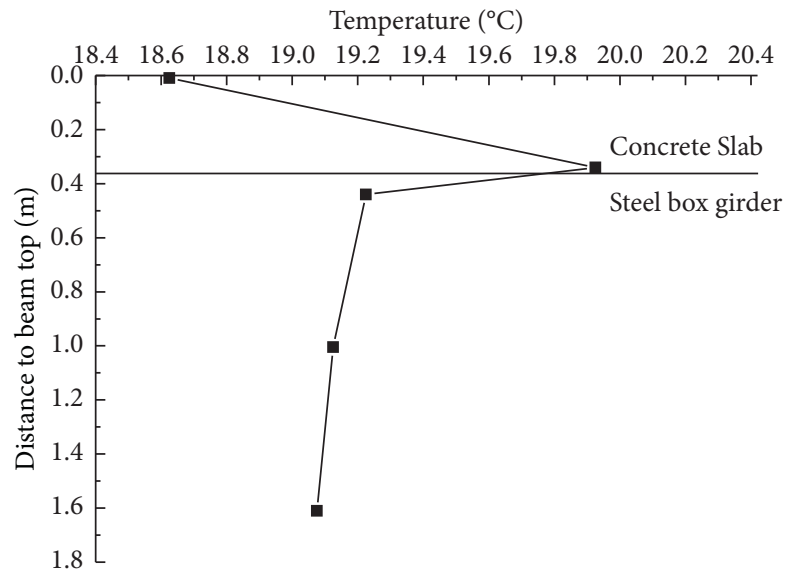

(b)

Figure 12: Most unfavourable curves of the temperature gradient on the vertical section. (a) Rise gradient after average. (b) Drop gradient after average. 


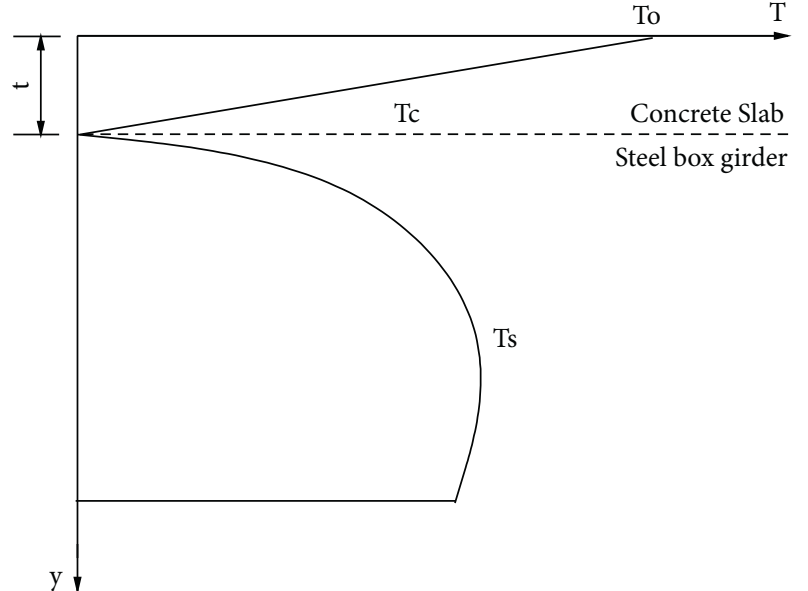

(a)

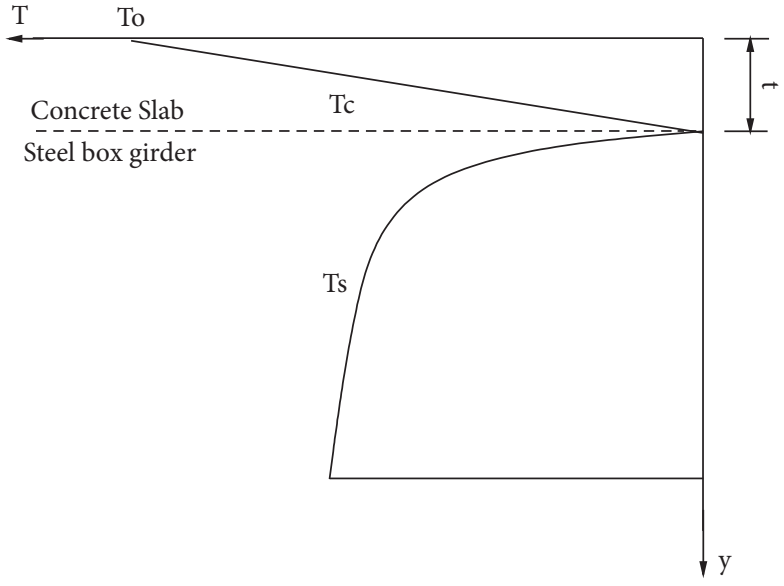

(b)

FIGURE 13: Most unfavourable curves of the temperature gradient on the vertical section. (a) Rise gradient after fitting. (b) Drop gradient after fitting.

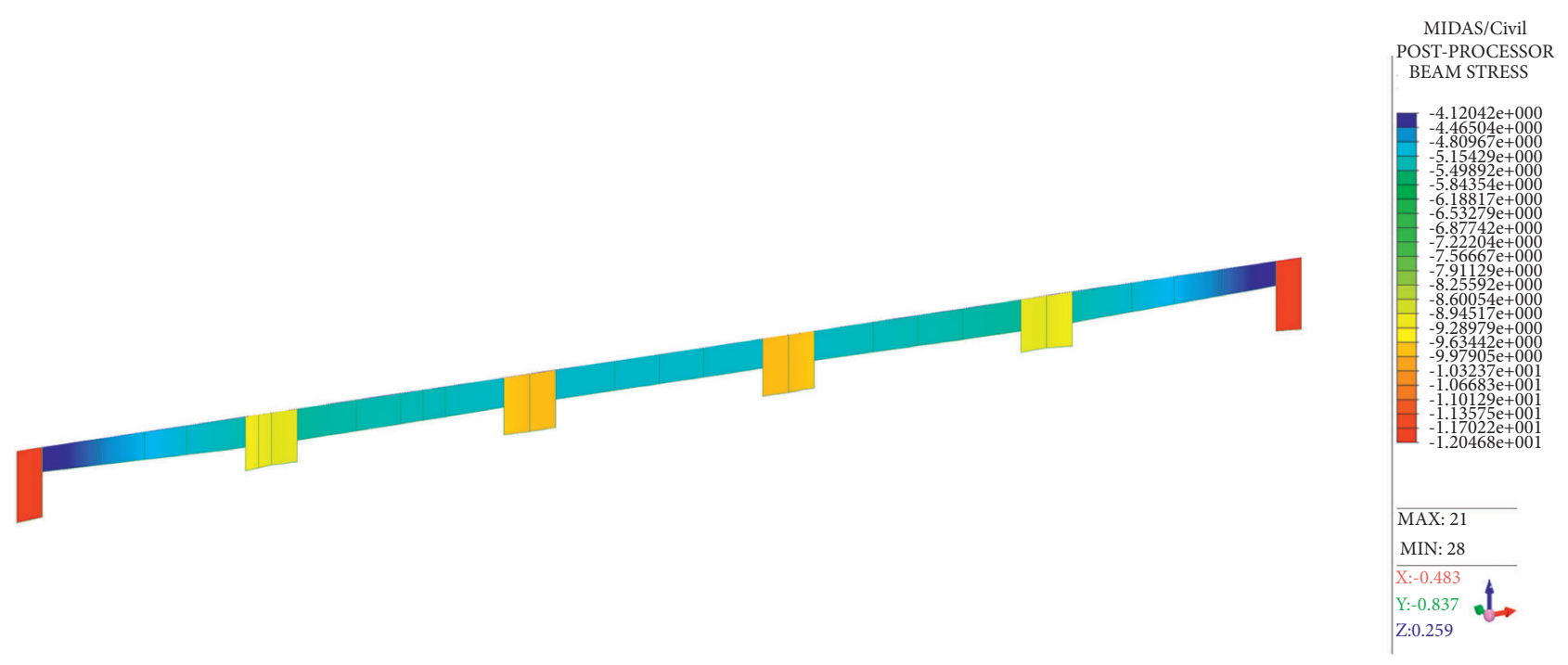

(a)

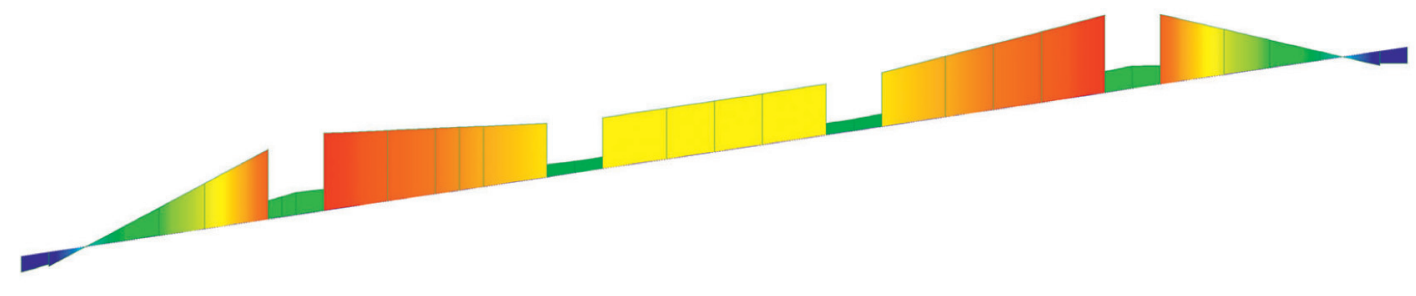

MIDAS/Civil POST-PROCESSOR

BEAM STRESS

$5.9651 \mathrm{e}+001$
$5.6525 \mathrm{e}+00$
$5.33962 \mathrm{e}+001$

(b)

FIGURE 14: Stress diagram of the steel-concrete composite bridge under a rise gradient. (a) Stress diagram of the concrete deck. (b) Stress diagram of the steel beam. 


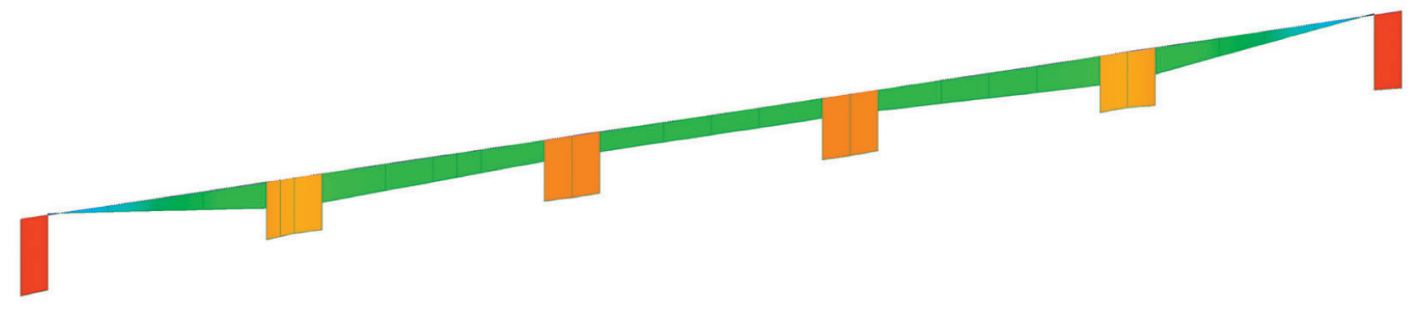

(a)

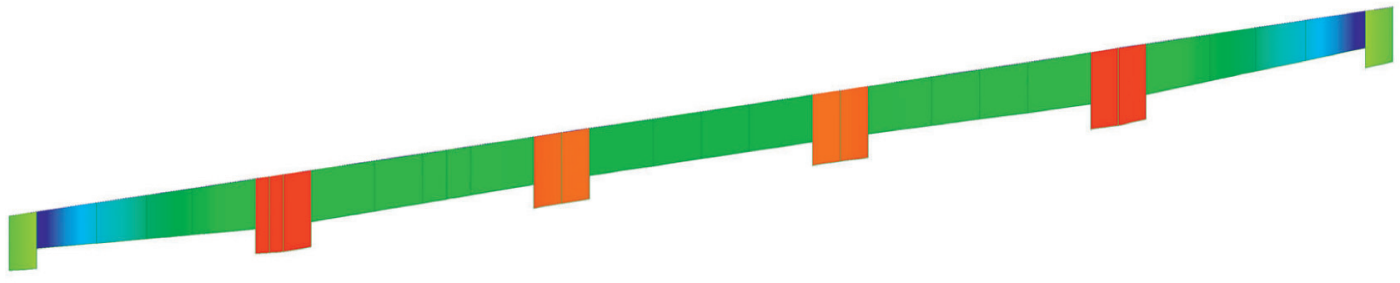

(b)

Figure 15: Stress diagram of the steel-concrete composite bridge under a drop gradient. (a) Stress diagram of the concrete deck. (b) Stress diagram of the steel beam.

concluded that the heating gradient is in the form of a quadratic parabola and that the cooling gradient is in the form of a logarithmic function.

The temperature gradient models of the concrete section and steel box girder section are fitted to the temperature difference at each measuring point. The fitting results are shown in Figure 13.

In Figure 13, To is the top temperature of the concrete bridge deck, $T c$ is the vertical temperature gradient curve of the concrete bridge deck section, $T s$ is the vertical temperature gradient curve of the steel box girder section, and $t$ is the thickness of the concrete bridge deck. The $y$ axis is the distance from the section position to the beam top, unit: $\mathrm{m}$. The expression of the temperature rise curve is as follows:

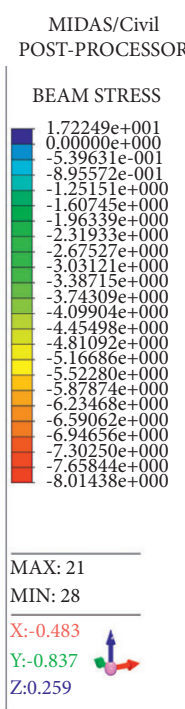

MIDAS/Civil POST-PROCESSOR

BEAM STRESS

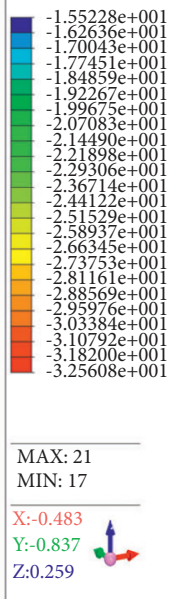




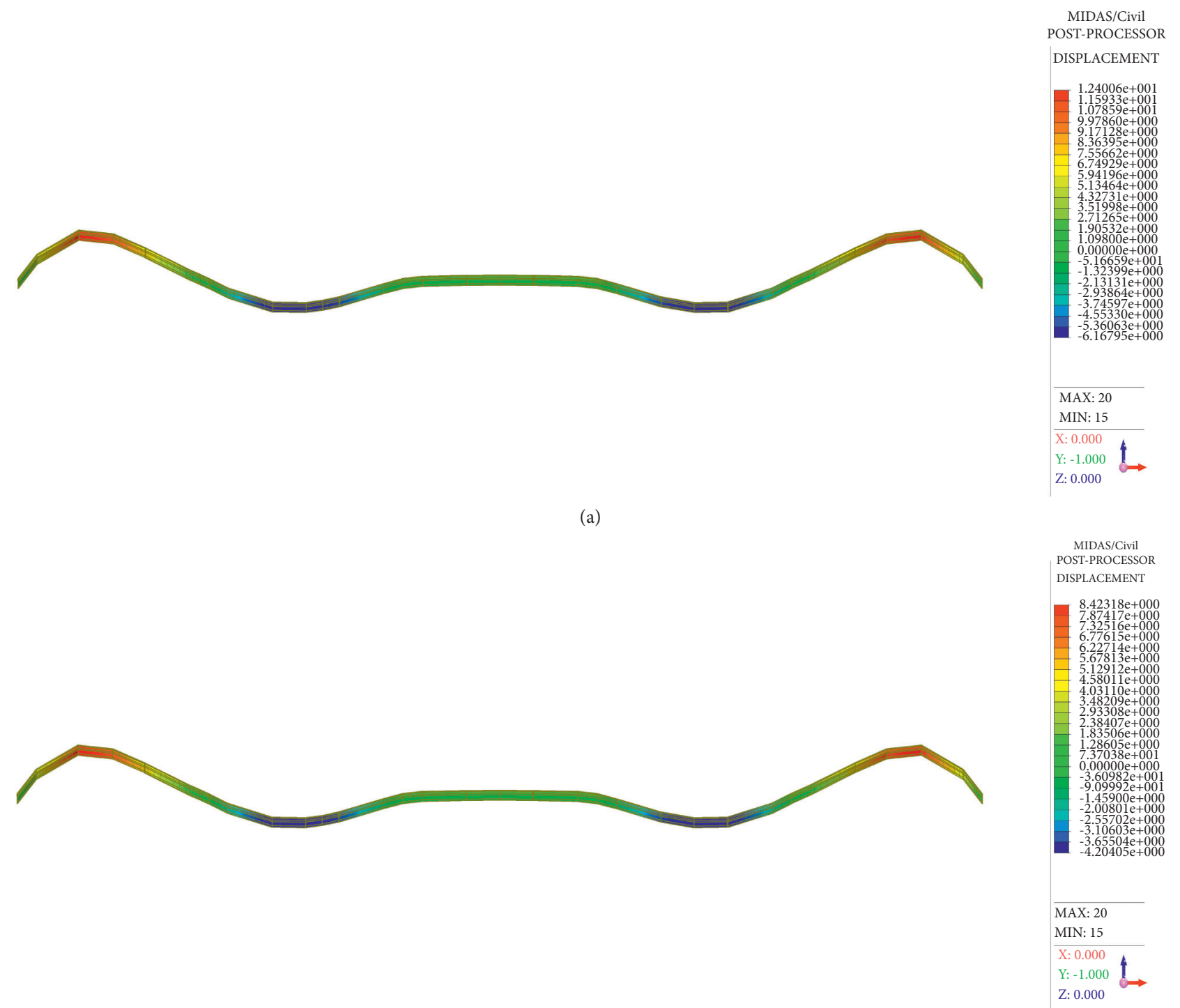

(b)

FiguRe 16: Displacement diagram of the steel-concrete composite beam under a temperature gradient. (a) Rise gradient displacement diagram. (b) Drop gradient displacement diagram.

bridge orientation, structural type, and material, the vertical temperature gradient may be different, and the code value is not necessarily accurate.

3.5. Effect of the Temperature Gradient on the Stress. According to the field-measured temperature gradient, the influence of the temperature gradient on the stress and displacement of the bridge deck and steel beam is explored. According to the analysis of the measured data in Tables 2 and 3, the most unfavourable temperature gradient curve of temperature gradient rise and drop is fitted according to Figure 13, and the load is applied in consideration of the height at the measuring point. In the analysis of the influence of the vertical temperature gradient on the stress of the composite beam section, according to the two loading modes of rising and falling temperature gradients, the structural stresses of the concrete deck and steel beam are compared and analysed, as shown in Figures 14 and 15.

From the above analysis of the temperature gradient stress diagram, the following results are obtained:

(1) In the rise gradient mode, except for the compression near the supports at both ends of the bridge span is 12.31 MPa, the remaining parts of the steel beam are in tension, and the maximum value is $59.65 \mathrm{MPa}$, which occurs near pier \#16 of the second span and pier \#19 of the fourth span, while the stress at the support is less than that at the midspan section. Besides, the whole section of the concrete deck is in compression, and the compressive stress near the support is greater than that at other parts. The maximum stress at the fulcrum at both ends of the bridge span is $12.04 \mathrm{MPa}$. 
(2) In the drop gradient mode, the whole section of the steel beam is in compression, the maximum compressive stress is $32.56 \mathrm{MPa}$ at piers \#16 and \#19, and the stress at the other supports is greater than that at the midspan section. While the concrete bridge deck is in the tension state at the support position, with a maximum tensile stress of $0.17 \mathrm{MPa}$, and the remaining parts of the concrete bridge deck are in compression, the maximum compressive stress at other spans is $8.01 \mathrm{MPa}$.

3.6. Influence of the Temperature Gradient on the Displacement. Figure 16 shows that under the action of a vertical temperature gradient, the beam body has a certain deformation, in which the deformation under the action of a positive temperature difference is $6.16-12.40 \mathrm{~mm}$, and the deformation under the action of a negative temperature difference is $4.20-8.42 \mathrm{~mm}$.

\section{Conclusion}

In this paper, the temperature field, temperature gradient, and effect of steel-concrete composite beam bridges of the Binhe West Road are studied, and the temperature field distribution of steel-concrete composite beam bridges is discussed:

(1) In this paper, the steel-concrete composite box girder bridge is aligned in the north-south direction. According to experience, due to the influence of sunlight, there is a large temperature difference between the eastern and western sides of the bridge in the afternoon, but the measured difference is not notable. With increasing atmospheric temperature, the influence of sunlight radiation on the temperature of the bridge structure gradually weakens, and the temperature change mainly comes from the heat transfer of the surrounding environment.

(2) Observation of the local temperature field at the joint of the steel-concrete composite beam indicates that although there is a certain degree of temperature difference between the two materials in the local range (most of the time due to the heat transfer between the concrete slab and the steel beam structure), there is a temperature difference at the joint of the structure, but the difference is not large.

(3) Previous research on the temperature effect of composite box girder bridges focused on monitoring during the sunshine period, and most of that work ignored the influence of cooling at night. In this paper, the steel-concrete composite box girder bridge is continuously measured in a day. By comparing and analysing the measured data, the most unfavourable temperature gradient in the vertical section is simulated and calculated, including two modes of rising and cooling. There are some differences with the latest code of the
Specifications for Design and Construction of Highway Steel-Concrete Composite Bridge, which can provide a reference for local bridge design.

\section{Data Availability}

The testing and analysis data used to support the findings of this study are included within the article.

\section{Disclosure}

The funders had no role in the design of the study; in the collection, analyses, or interpretation of data; in the writing of the manuscript; or in the decision to publish the results.

\section{Conflicts of Interest}

The authors declare no conflicts of interest.

\section{Acknowledgments}

This research was funded by National Natural Science Foundation of China (grant nos. 51738004 and 51868006) and High-Level Innovation Team and Outstanding Scholar Plan of Guangxi High Colleges.

\section{References}

[1] B. Murphy and M. Yarnold, "Temperature-driven structural identification of a steel girder bridge with an integral abutment," Engineering Structures, vol. 155, pp. 209-221, 2018.

[2] D. Pawlus, "Stability of three-layered annular plate in stationary temperature field," Thin-Walled Structures, vol. 144, Article ID 106280, 2019.

[3] L. Zhou, Y. Xia, J. M. W. Brownjohn, and K. Y. Koo, "Temperature analysis of a long-span suspension bridge based on field monitoring and numerical simulation," Journal of Bridge Engineering, vol. 21, no. 1, Article ID 04015027, 2016.

[4] T. Tao, H. Wang, Q. Zhu, Z. Zou, J. Li, and L. Wang, "Longterm temperature field of steel-box girder of a long-span bridge: measurement and simulation," Engineering Structures, vol. 236, Article ID 111924, 2021.

[5] G.-D. Zhou, T.-H. Yi, B. Chen, and H. Zhang, "A generalized Pareto distribution-based extreme value model of thermal gradients in a long-span bridge combining parameter updating," Advances in Structural Engineering, vol. 20, no. 2, pp. 202-213, 2017.

[6] JTG/T D64-01-2015, "Specifications for Design and Construction of Highway Steel-Concrete Composite Bridge," Ministry of Transport, Beijing, China, JTG/T D64-01-2015, 2015.

[7] Li Wang, Research on Mechanical Properties Duting Construction Stage and Temperatrure Field of Steel-Concrete Composite Structure Bridge, Beijing University Of Technology, Beijing, China, 2015.

[8] Q. Han, Analysis of the Temperature Effect on Steel-Concrete Composite Bridges, Beijing University Of Civil Engineering And Architecture, Beijing, China, 2015.

[9] M. T. Yarnold and F. L. Moon, "Temperature-based structural health monitoring baseline for long-span bridges," Engineering Structures, vol. 86, pp. 157-167, 2015. 
[10] Q. Xia, J. Zhang, Y. Tian, and Y. Zhang, "Experimental study of thermal effects on a long-span suspension bridge," Journal of Bridge Engineering, vol. 22, no. 7, Article ID 04017034, 2017.

[11] M. Tong, L. G. Tham, F. T. K. Au, and P. K. K. Lee, "Numerical modelling for temperature distribution in steel bridges," Computers \& Structures, vol. 79, no. 6, pp. 583-593, 2001.

[12] A. Jesus, P. Brommer, R. Westgate, K. Koo, J. Brownjohn, and I. Laory, "Bayesian structural identification of a long suspension bridge considering temperature and traffic load effects," Structural Health Monitoring, vol. 18, no. 4, pp. 1310-1323, 2019.

[13] W. Q. Xiang, L. Pei-heng, and J. Chi-yu, “Temperature analysis of steel-concrete composite girder caused by solar radiation [J]," Journal of Beijing University of Civil Engineering and Architecture, vol. 32, no. 2, pp. 22-27, 2016.

[14] W. Yao-Xu, Study on the Structural Behavior of Steel-concrete Composite Girders under the Effect of Sunshine Temperature Field, Southwest Jiaotong University, Chengdu, China, 2017.

[15] J. I. De-jun, L. Jiang, and Z.-F. Zhang, "Temperature effect analysis of steel-concrete composite girder cable-stayed bridge in arctic-alpine region [J]," Journal of Architecture and Civil Engineering, vol. 33, no. 1, pp. 113-119, 2016.

[16] T. Hossain, S. Segura, and A. M. Okeil, "Structural effects of temperature gradient on a continuous prestressed concrete girder bridge: analysis and field measurements," Struct Infrastruct Eng, vol. 16, pp. 1-12, 2020.

[17] C. W. Roeder, "Proposed design method for thermal bridge movements," Journal of Bridge Engineering, vol. 8, no. 1, pp. 12-19, 2003.

[18] X. U. Xiang-feng, "Temperature distribution of box girder with corrugated steel webs [J]," Journal of Chongqing Jianzhu University: Natural Science, vol. 37, no. 12, pp. 1-10, 2018.

[19] I. Laory, R. J. Westgate, J. M. W. Brownjohn, and I. F. C. Smith, "Temperature variations as load cases for structural identification," in Proceedings of the the 6th International Conference on Structural Health Monitoring of Intelligent Infrastructure, Hong Kong, 2013.

[20] Y. Xia, B. Chen, X.-q. Zhou, and Y.-l. Xu, "Field monitoring and numerical analysis of Tsing Ma Suspension Bridge temperature behavior," Structural Control and Health Monitoring, vol. 20, no. 4, pp. 560-575, 2013.

[21] T. H. T. Chan, L. Yu, H. Y. Tam, Y. Q. Ni, S. Y. Liu, and W. H. Chung, "Fiber Bragg grating sensors for structural health monitoring of Tsing Ma bridge: background and experimental observation," Engineering Structures, vol. 28, no. 5, pp. 648-659, 2006.

[22] C. Q. Miao and C. H. Shi, "Temperature gradient and its effect on flat steel box girder of long-span suspension bridge," Science China Technological Sciences, vol. 56, no. 8, pp. 1929-1939, 2013.

[23] A. Jesus, P. Brommer, Y. Zhu, and I. Laory, "Comprehensive Bayesian structural identification using temperature variation,” Engineering Structures, vol. 141, pp. 75-82, 2017.

[24] M. E. Warren and N. C. Dubbs, "Periodic temperature-based bearing assessment of a steel multigirder bridge," Transportation Research Record: J Transp Res Board, vol. 2642, pp. 26-34, 2017.

[25] N. A. Hoult, P. R. A. Fidler, I. J. Wassell, P. G. Hill, and C. R. Middleton, "Wireless structural health monitoring at the Humber Bridge UK," Proc Inst Civil Eng - Bridge Eng, vol. 161, no. 4, pp. 189-195, 2008.

[26] Y. Zhou and L. M. Sun, "Insights into temperature effects on structural deformation of a cable-stayed bridge based on structural health monitoring," Structural Health Monitoring, vol. 18, no. 3, pp. 778-791, 2019.

[27] M. T. Yarnold, F. L. Moon, and A. E. Aktan, "Temperaturebased structural identification of long-span bridges," Journal of Structural Engineering, vol. 141, 2015.

[28] R. Kromanis and P. Kripakaran, "SHM of bridges: characterising thermal response and detecting anomaly events using a temperature-based measurement interpretation approach," J Civ Struct Health Monit, vol. 6, pp. 237-254, 2016.

[29] M. T. Yarnold and S. G. Wilson, "Forensic investigation of the route 61 bridge," in Proceedings of the Structures Congress, pp. 309-321, Portland, Oregon, April 2015.

[30] Y. Cao, J. Yim, Y. Zhao, and M. L. Wang, “Temperature effects on cable stayed bridge using health monitoring system: a case study," Structural Health Monitoring, vol. 10, pp. 523-537, 2011.

[31] Y.-F. Duan, Y. Li, and Y.-Q. Xiang, "Strain-temperature correlation analysis of a tied arch bridge using monitoring data," in Proceedings of the International Conference on Multimedia Technology, pp. 6025-6028, Hangzhou, China, July 2011.

[32] Y. L. Ding, G. D. Zhou, A. Q. Li, and G. X. Wang, “Thermal field characteristic analysis of steel box girder based on longterm measurement data," Int J Steel Struct, vol. 12, no. 2, pp. 219-232, 2012.

[33] Y. L. Xu, B. Chen, C. L. Ng, K. Y. Wong, and W. Y. Chan, "Monitoring temperature effect on a long suspension bridge," Structural Control and Health Monitoring, vol. 17, no. 6, pp. 632-653, 2010.

[34] D. Wang, Y. M. Liu, and Y. Liu, "3D temperature gradient effect on a steel-concrete composite deck in a suspension bridge with field monitoring data," Structural Control and Health Monitoring, vol. 25, no. 7, p. e2179, 2018.

[35] L. Lawson, K. L. Ryan, and I. G. Buckle, "Bridge temperature profiles revisited: thermal analyses based on recent meteorological data from Nevada," Journal of Bridge Engineering, vol. 25, no. 1, Article ID 04019124, 2020. 